\title{
Experimental demonstration of chaotic instability in biological nitrification
}

\author{
David W Graham ${ }^{1,2}$, Charles W Knapp ${ }^{1,2}$, Erik S Van Vleck ${ }^{3}$, Katie Bloor ${ }^{1}$, Teresa B Lane ${ }^{2}$ \\ and Christopher E Graham ${ }^{4}$ \\ ${ }^{1}$ School of Civil Engineering and Geosciences, Newcastle University, Newcastle Upon Tyne, UK; ${ }^{2}$ Department \\ of Civil, Environmental, and Architectural Engineering, University of Kansas, Lawrence, KS, USA; \\ ${ }^{3}$ Department of Mathematics, University of Kansas, Lawrence, KS, USA and ${ }^{4}$ Photon Wind Research Ltd, \\ Surrey, British Columbia, Canada
}

\begin{abstract}
Biological nitrification (that is, $\mathrm{NH}_{3} \rightarrow \mathrm{NO}_{2}^{-} \rightarrow \mathrm{NO}_{3}^{-}$) is a key reaction in the global nitrogen cycle (Ncycle); however, it is also known anecdotally to be unpredictable and sometimes fails inexplicably. Understanding the basis of unpredictability in nitrification is critical because the loss or impairment of this function might influence the balance of nitrogen in the environment and also has biotechnological implications. One explanation for unpredictability is the presence of chaotic behavior; however, proving such behavior from experimental data is not trivial, especially in a complex microbial community. Here, we show that chaotic behavior is central to stability in nitrification because of a fragile mutualistic relationship between ammonia-oxidizing bacteria (AOB) and nitrite-oxidizing bacteria (NOB), the two major guilds in nitrification. Three parallel chemostats containing mixed microbial communities were fed complex media for 207 days, and nitrification performance, and abundances of $\mathrm{AOB}, \mathrm{NOB}$, total bacteria and protozoa were quantified over time. Lyapunov exponent calculations, supported by surrogate data and other tests, showed that all guilds were sensitive to initial conditions, suggesting broad chaotic behavior. However, NOB were most unstable among guilds and displayed a different general pattern of instability. Further, NOB variability was maximized when $A O B$ were most unstable, which resulted in erratic nitrification including significant $\mathrm{NO}_{2}^{-}$accumulation. We conclude that nitrification is prone to chaotic behavior because of a fragile AOB-NOB mutualism, which must be considered in all systems that depend on this critical reaction.
\end{abstract}

The ISME Journal (2007) 1, 385-393; doi:10.1038/ismej.2007.45; published online 12 July 2007

Subject Category: microbial population and community ecology

Keywords: chaotic behavior; Lyapunov exponents; nitrification; mutualism; N-cycle

\section{Introduction}

All microbial ecosystems are comprised of diverse groups of organisms that fulfill similar ecological interactions as macroscopic systems. Predation, competition and mutualism are all enacted and can result in complex behavior, including chaos (May, 1974; Huisman and Weissing, 1999). For example, recent experimental data showed that a protozoan predator conditionally displayed chaotic behavior in a two prey-one predator axenic culture (Becks et al., 2005). Although this result is interesting, real microbial communities are neither this simple nor can be studied with such limited data

Correspondence: Professor DW Graham, School of Civil Engineering and Geosciences, Newcastle University, Cassie Building, Newcastle Upon Tyne NE1 7RU, UK.

E-mail: d.graham@ncl.ac.uk

Received 20 March 2007; revised 17 May 2007; accepted 18 May 2007; published online 12 July 2007
(Juretschko et al., 2002; Wagner and Loy, 2002; Turchin, 2003); a more practical question in real ecosystems is whether guilds of populations that perform important biochemical functions display chaotic behavior as groups. Determining the possibility of chaotic behavior in microbial guilds that perform key functions, such as biological nitrification, is critical to understanding sustainability of such processes that have both environmental (for example, the biogeochemical nitrogen cycle $(\mathrm{N}-$ cycle)) and biotechnological (for example, waste treatment processes) significance.

The goal of this work was to experimentally assess the basis of stability in nitrification, including the possibility of chaotic behavior. Nitrification was chosen for study because it is ubiquitous in nature and it is anecdotally known to be 'unpredictable' (Vitousek et al., 1997; Wagner et al., 2002; Rittman and McCarty, 2003). Furthermore, chaotic instability is a legitimate explanation for unpredictability since this process involves two mutually dependent 
microbial guilds (ammonia-oxidizing bacteria (AOB) that convert $\mathrm{NH}_{3}$ to $\mathrm{NO}_{2}^{-}$and nitrite-oxidizing bacteria (NOB) that convert $\mathrm{NO}_{2}^{-}$to $\mathrm{NO}_{3}^{-}$) that reside in a mixed microbial community (Wagner and Loy, 2002; Rittman and McCarty, 2003), and such mutualisms have been mathematically shown to conditionally display chaotic behavior (Lopez-Ruiz and Fournier-Prunaret, 2004). Finally, nitrifyingbacteria are slow growers, nutritionally inflexible, sensitive to inhibitors and less phylogenetically diverse than many other key functional guilds (Balmelle et al., 1992; Jonsson et al., 2000; Wagner et al., 2002; Rittman and McCarty, 2003). As such, destabilization can result in unrecoverable loss of function, which can have major effects on natural and engineered systems reliant on the reaction (Vitousek et al., 1997; Jonsson et al., 2000).

The possibility of chaotic behavior in nitrifying systems was suggested over 20 years ago (Dean, 1985); however, no experimental proof exists. This has been largely due to inadequate detection methods for monitoring specific microbial guilds in real systems, and the general difficulty of gaining enough and appropriate experimental data to satisfy the needs of rigorous mathematical analysis (Turchin, 2003). With the advent of new molecular biological tools (Daims et al., 2001; Coskuner et al., 2005; Wagner et al., 2006), detection issues are less restrictive, and mathematical methods exist for calculating indicators of dynamic instability, such as Lyapunov exponents (LEs), from short time series data (Rosenstein et al., 1993, 1994). Nevertheless, gaining 'conclusive' proof of chaotic behavior from limited data is not trivial (Costantino et al., 1997; Fussmann et al., 2000; Turchin, 2003). LEs can be calculated from experimental results, but such exponents only describe trends in stability and it is tenuous to extend local LEs to the entire system. However, experimental LEs, when supported by the mathematical validation of determinism and nonlinearity in the time series, can provide valuable insights into the basis of stability in a process like nitrification.

In this study, three aerobic chemostats were fed complex liquid media at different dilution rates; AOB, NOB and total bacteria, and protozoan guilds were monitored over time using real-time PCR and direct enumeration, respectively. Chemostats were employed because community stability is influenced by dilution rate (Dean, 1985; Funasaki and Kot, 1993; Vayenas and Pavlou, 1999; Kooi and Boer, 2003), and complex (non-selective) growth media were used because we wanted to examine nitrification within a realistic mixed microbial community. This approach made guild quantification and mathematical analysis more difficult, but it also permits the study of guild dynamics in a quasi-natural setting. Finally, chemostat dilution rates were chosen to differentially stress nitrifying guilds in different reactors, and nitrification efficiency was quantified to assess microbial function relative to guild stability.

\section{Materials and methods}

Experimental design and reactor operations

Three highly controlled aerobic bioreactors (B Braun Biotech, Goettingen, Germany) were seeded with a combination of domestic wastewater from an actively nitrifying wastewater treatment plant $(33 \%)$ and simulated wastewater (67\%; see Supplementary Information for composition). The reactors were then fed simulated wastewater (only) in parallel for over 300 days, initially operated as batch and filland-draw units to increase biosolids levels, and then as chemostats with dilution rates of $0.1,0.3$ and $0.83 \mathrm{day}^{-1}$, respectively (Supplementary Information). Although no replicate reactors were employed in the experimental design (largely due to cost and operational practicality), the three reactors were monitored in fine detail with a high-level quality control, which ensured as much stationarity as possible in the non-replicate reactors. As examples, media were prepared identically every 2-3 days in 20 - $\mathrm{L}$ carboys retained in a $4{ }^{\circ} \mathrm{C}$ refrigerator. The feed carboy was fitted with a drawtube that passed through a port in the refrigerator wall to pumps that fed the same media in parallel to each reactor at carefully regulated rates. The actual volume of media removed differed among reactors, but carboy feed volumes and reactor effluent volumes were logged daily to verify proper operation of the pumps and validate flow rates. Lines were replaced weekly with clean and presterilized lines.

Biostat $i$ Twin Controllers continuously monitored dissolved oxygen (DO) and $\mathrm{pH}$, and regulated reactor operations. Compressed air was provided to the reactors through sterile filters (Gelman $0.2 \mu \mathrm{m}$ PTFE; Pall Corporation, East Hills, NY, USA) at rates required to maintain constant DO levels. Twin-paddles were operated at 60 r.p.m. to promote oxygen mass transfer and ensure solids were suspended in each reactor. Reactor temperature and DO were maintained at $25^{\circ} \mathrm{C}$ and $\sim 7.0 \mathrm{mg} / \mathrm{l}$, respectively, and a condensation unit was used to minimize liquid evaporation.

\section{Sample collection and chemical routine analysis}

The reactors were sampled very systematically to quantify guild abundances and reactor performance over time. Physical-chemical conditions were monitored using real-time sensors (for example, $\mathrm{pH}, \mathrm{DO}$, temperature) and by the collection of composite liquid samples for daily chemical analyses. Liquid samples were continuously collected using a sipping sampler located at the water surface of each reactor, which was connected to a peristaltic pump leading to effluent collectors that were kept at $4^{\circ} \mathrm{C}$. Composite samples were retrieved each morning and processed for daily chemical analysis, which included total nitrogen (TN), total and volatile suspended solids (TSS and VSS), $\mathrm{NH}_{3}-\mathrm{N}, \mathrm{NO}_{2}^{-}, \mathrm{NO}_{3}^{-}$, chemical oxygen demand and alkalinity (APHA et al., 1998). 
To verify that the sipper was not biasing samples, bulk solution samples were intermittently collected from mid-depth in each reactor through separate sampling ports. Correlation analysis on biosolids levels (that is, TSS/VSS) was performed on samples from each source to verify that sipped versus manually withdrawn samples provided the same information. The two methods significantly correlated ( $t$-test, $P<0.05)$. As an additional precaution against the retention of solids in the reactors (as biofilms or large floc), reactor mixing rates were increased to 500 r.p.m. for $5 \mathrm{~min}$ each day, immediately after composite sample collection, to resuspend solids and scour the reactor walls before commencement of the next sampling cycle.

\section{Biological sample processing and analysis}

Samples for quantifying protozoa and bacterial guilds in the reactors were collected every 2 days. However, different preparation methods were used in protozoa enumeration and real-time PCR quantification of bacterial guilds. For protozoa, a 10-ml aliquot of unfiltered sample was removed and stored at $4{ }^{\circ} \mathrm{C}$ in $1 \%$ Lugol's solution before direct microscopic counting using inverted microscopy (Olympus at $\times 200$ magnification). Each protozoa was tallied (and identified when possible) and sized using a calibrated Whipple grid. Protozoa counts for each sample were collated by number and size, which were used to calculate biovolumes according to RuttnerKolisko (1977) and biomasses according to Fry (1990).

Procedures for molecular biological analysis of bacterial abundances are described in Supplementary information. In summary, three 2.0-ml subsamples were removed from collected biomass samples (parallel to protozoa samples), and DNA was extracted from the pellets using the DNeasy Tissue kit with lysozyme pretreatment (Qiagen, Valencia, CA, USA). The extracted DNA was eluted into $200 \mu \mathrm{l}$ of molecular-grade water and then stored at $-20^{\circ} \mathrm{C}$.
Abundances of 16S-rRNA genes were quantified using real-time PCR (Bio-Rad iCycler, Hercules, CA, USA) with primers and Taqman probes for AOB (Kowalchuk et al., 1997; Hermansson and Lindgren, 2001), total bacteria (Harms et al., 2003) and NOB, which are summarized in Table 1 (see Supplementary Information for specificities; ammonia-oxidizing archaea were also screened using the method of Park et al. (2006), but no signals were detected). Single primer/probe sets were used to quantify $\mathrm{AOB}$ and total bacteria, whereas NOB abundance was the combined signal from Nitrobacter spp. and Nitrospira spp. primer/ probe sets. Standards included plasmids containing cloned 16S-rRNA from unspecified AOB (IM Head and C Linacre, unpublished results), Nitrobacter sp. (GenBank no. DQ388518; Hawkins et al., 2006) and Nitrospira defluvii (no. DQ059545; Spieck et al., 2006).

To compare PCR measures of bacterial abundance and protozoa counts, gene abundance numbers were converted to biomass values (as $\mu \mathrm{g}$-C/l; Supplementary Information), using estimated rRNA operon copies per cell (Klappenbach et al., 2001), cell biovolumes (Bergey et al., 1994; Posch et al., 2001; Koops et al., 2003) and allometric conversion factors (Loferer-Krössbacher et al., 1998). It is important to note that although these biomass calculations required many assumptions, the main criterion for calculating LEs is the 'relative' precision of data within each time series; therefore, as long as consistent conversions are made within the series, the same LEs result.

\section{Calculation of LEs}

LEs were calculated using the method of Rosenstein et al. (1993, 1994) with L1D2 (www.physionet.org/ physiotools/lyapunov/l1d2/) using directly measured abundance data from the chemostats. The goal was to quantify the exponential divergence of initially close state-space trajectories by measuring

Table 1 Oligonucleotide primers and Taqman probe sequences used in the experiment

\begin{tabular}{|c|c|c|c|c|}
\hline Target organism & Primer/probe & Sequence $\left(5^{\prime}-3^{\prime}\right)$ & $\mathrm{T}_{a}\left({ }^{\circ} \mathrm{C}\right)$ & Reference \\
\hline \multirow[t]{4}{*}{ AOB } & CTO 189fA/B & GGAGRAAAGCAGGGGATCG & 60 & Kowalchuk et al. (1997) \\
\hline & CTO 189fC & GGAGGAAAGTAGGGGATCG & & \\
\hline & RT1r & CGTCCTCTCAGACCARCTACTG & & Hermansson and Lindgren (2001) \\
\hline & TMP1 & FAM-CAACTAGCTAATCAGRCATCRGCCGCTC-TAMRA & & \\
\hline \multirow[t]{3}{*}{ Nitrospira spp. } & Nspra-675f & GCGGTGAAATGCGTAGAKATCG & 58 & \\
\hline & Nspra-746r & TCAGCGTCAGRWAYGTTCCAGAG & & \\
\hline & Nspra-723Taq & FAM-CGCCGCCTTCGCCACCG-TAMRA & & \\
\hline \multirow[t]{3}{*}{ Nitrobacter spp. } & Nitro-1198f & ACCCCTAGCAAATCTCAAAAAACCG & 58 & \\
\hline & Nitro-1423r & CTTCACCCCAGTCGCTGACC & & \\
\hline & Nitro-1374Taq & FAM-AACCCGCAAGGAGGCAGCCGACC-TAMRA & & \\
\hline \multirow[t]{3}{*}{ 'Total' bacteria } & $1055 f$ & ATGGCTGTCGTCAGCT & 50 & Harms et al. (2003) \\
\hline & $1392 \mathrm{r}$ & ACGGGCGGTGTGTAC & & \\
\hline & 16STaq1115 & HEX-CAACGAGCGCAACCC-TAMRA & & \\
\hline
\end{tabular}

Abbreviation: AOB, ammonia-oxidizing bacteria. 
the mean rate of separation of nearest neighbors while excluding false nearest neighbors. LEs were estimated by the slope of the line obtained by linear least squares of the log-transformed divergence. Calculation of LE values used guild abundances measured every second day, which provided 104 uniformly distributed time points.

The following parameter values were employed in L1D2. A time delay of $J=3$ was used for all reported calculations since this resulted in an autocorrelation function of approximately $(1-1 / e)$ (Rosenstein et al., 1993) or less in all guild-chemostat combinations. Embedding dimensions of $m=4,5,6$ were used since convergence was observed in computed LE values for these embedding dimensions (see later). The time delay and embedding dimensions employed are consistent with the geometric method (Rosenstein et al., 1994) for determining time delays. In order to exclude false nearest neighbors, a Theiler window of $w=20$ was employed. The use of $w=20$ was arrived upon by inspection of space time separation plots (Provenzale et al., 1992; Kantz and Schreiber, 2004) for all guild-chemostat combinations that had been obtained using the routine 'stp' in TISEAN; and by examination of $\mathrm{LE}$ values assuming $w=10,15,20,25$, 30. Sensitivity analysis was performed by examining the dependence of calculated LEs on time delay and embedding dimension parameters; parameter values were chosen that minimized variation in the estimated LE for each guild.

\section{Demonstrating determinism and nonlinearity in the time series}

To verify that the data were not dominated by noise and had underlying deterministic trends, two methods were employed (see Supplementary Information for mathematical details). First, a modified version of the Pimm-Redfearn analysis of variability was used to assess whether variability was dominated by long-term deterministic trends rather than by short-term 'noise' (Rohani et al., 2004). Second, detrended fluctuation analysis was performed to examine innate variability in detected long-range correlations (Peng et al., 1995). To examine determinism and nonlinearity in the data, linear versus nonlinear prediction models were assessed. Specifically, Volterra-Wiener series of degree 1 (linear) and degree 2 (nonlinear) were fitted to the data, and in-sample root-mean-square (r.m.s.) errors were compared, with smaller nonlinear errors indicating nonlinearity (Barahona and Poon, 1996). In-sample r.m.s. error in the Volterra-Wiener models was also used to test the null hypothesis of linearity on surrogate data sets. Polished, amplitude-adjusted Fourier-based surrogate series were generated from experimental data using TISEAN 2.1 (Schreiber and Schmitz, 1996), and ranking of the error statistic in the distribution over 19 surrogate time series was examined. A ranking of one was used to reject the hypothesis of linearity with $95 \%$ significance.
Calculation of coefficient of variation in abundance time-series data

Rolling coefficient of variation (CV) of guild abundances was estimated for each time series to describe how guild variance over time might relate to process performance. Variance has been considered as a possible forecasting tool for predicting dynamic shifts in other systems that display chaotic behavior (Scheffer and Carpenter, 2003; Carpenter and Brock, 2006), and it was desired to test whether rolling CV might correlate with nitrification efficiency in our systems. Further, recent results have shown that microbial process instability can affect performance (Gentile et al., 2007; Miura et al., 2007), although no quantitative predictive tool has been proposed.

As there is no precedent to this procedure in microbial systems, it was necessary to determine the most appropriate length of time in the time series over which to best calculate the rolling CV. Specifically, rolling CV is calculated as the standard deviation of measured abundances over $n$ days before when performance was measured, divided by the mean over the same period. To examine possible options, many rolling CV values were calculated from each time series, using different numbers of preceding days $n$. The calculation was performed for $n=3-20$, and it was found that CV for $n$ between 7 and 11 (it varied slightly among guilds) always correlated best with process performance. Interestingly, this time-length consistently corresponded with the mean wavelength of the abundance cycle for each guild. As such, one cycle of abundance data was used as the standard for calculating rolling $\mathrm{CV}$, which is actually logical because it describes behavior in one cycle immediately before determining performance (that is, it is not skewed by out-of-cycle variation). Although this approach was successful, work is needed to study the underlying basis of the method and verify its broader utility.

\section{Results}

Guild abundance patterns and chemostat performance Three chemostats were monitored daily under quasi-stationary operating conditions for 207 days at dilution rates of $0.1,0.3$, and $0.83 \mathrm{day}^{-1}$, respectively, with the 0.83 day $^{-1}$ unit being operated close to washout (based on assumed maximum specific growth rates for nitrifying bacteria of 1.0-1.5 day ${ }^{-1}$ at $25^{\circ} \mathrm{C}$; Rittman and McCarty, 2003). Figures 1a, b and c summarize protozoa (the presumed dominant predator), AOB, NOB and total bacteria guild abundances over time in the reactors. Variations in abundances were always cyclic, which is characteristic of most biological systems (May, 1974; Dean, 1985; Huisman and Weissing, 1999); however, abundance amplitudes varied greatly among guilds. In general, amplitudes were larger and more variable 


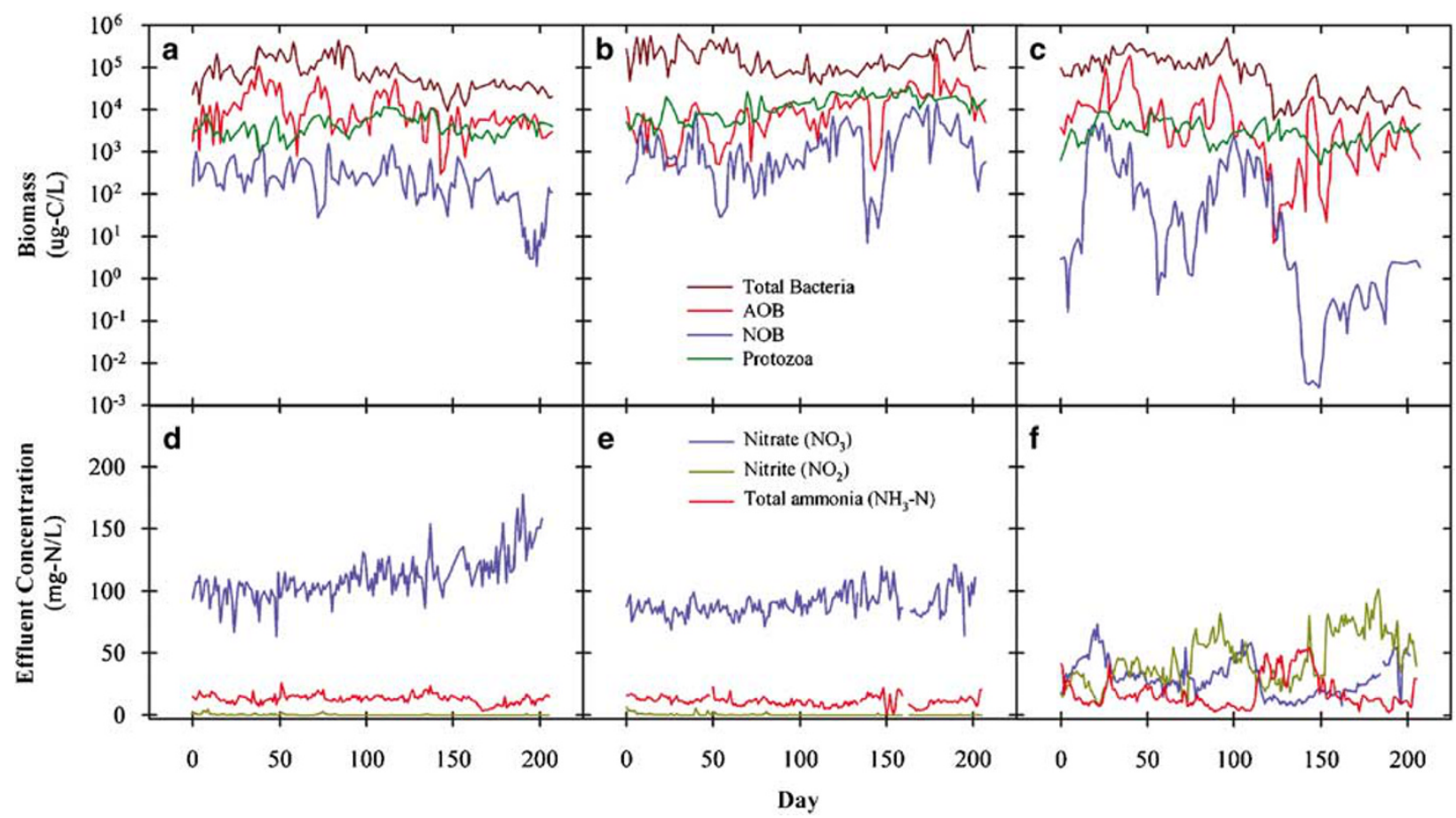

Figure 1 Guild abundances (as $\mu \mathrm{g}-\mathrm{C} / \mathrm{l}$ ) over time in the chemostats with dilutions of (a) 0.1 day $^{-1}$, (b) 0.3 day $^{-1}$ and (c) 0.83 day $^{-1}$. Complementary chemostat effluent nitrogen levels for the (d) 0.1 day $^{-1}$, (e) 0.3 day $^{-1}$ and (f) 0.83 day $^{-1}$ reactors.

Table 2 Average organic carbon and nitrogen levels in chemostat effluents

\begin{tabular}{|c|c|c|c|}
\hline Dilution rate & 0.1 day $^{-1}$ & $0.33 d_{a y}^{-1}$ & $0.83 d^{2} a y^{-1}$ \\
\hline \multicolumn{4}{|c|}{ Effluent organic carbon levels as mg-COD/l } \\
\hline $\mathrm{COD}_{\text {out }}^{\mathrm{a}}$ & $120.2(8.64)^{\mathrm{b}}$ & $105.3(6.62)$ & $166.2(7.72)$ \\
\hline $\mathrm{NH}_{3}-\mathrm{N}$ & $12.8(0.48)$ & $11.0(0.49)$ & $18.1(1.76)$ \\
\hline \multicolumn{4}{|c|}{ Effluent nitrogen levels as $\mathrm{mg}-\mathrm{N} / \mathrm{l}$} \\
\hline $\mathrm{NO}_{2}^{-}$ & $0.38(0.09)$ & $0.45(0.13)$ & $43.9(2.83)$ \\
\hline $\mathrm{NO}_{3}^{-}$ & 111 (2.39) & $90.1(1.41)$ & $30.2(1.96)$ \\
\hline
\end{tabular}

Abbreviations: COD, chemical oxygen demand; TN, total nitrogen. ${ }^{a}$ Chemostat influent organic carbon (as COD) and TN levels were $520 \mathrm{mg}-\mathrm{COD} / \mathrm{l}$ and $120 \mathrm{mg}-\mathrm{N} / \mathrm{l}$ (including $\mathrm{NH}_{3}-\mathrm{N} \sim 25-30 \mathrm{mg}-\mathrm{N} / \mathrm{l}$ ), respectively.

beported average effluent levels based on $n>190$ samples per parameter per chemostat collected over the 207-day experiment; bracketed values represent the $95 \%$ confidence intervals.

as dilution rate increased. NOB abundances were most variable among guilds, ranging by seven orders of magnitude in the 0.83 day $^{-1}$ reactor.

Table 2 and Figures 1d, e and f present parallel nitrification performance data among chemostats. The 0.1 and 0.3 day $^{-1}$ units had $\sim 90 \%$ and $75 \% \mathrm{~N}-$ conversion efficiencies (defined as the percent conversion of influent $\mathrm{TN}$ to $\mathrm{NO}_{3}^{-}$in the reactor effluent), respectively, whereas $\mathrm{N}$-conversion efficiency in the 0.83 day $^{-1}$ reactor was very variable, ranging from about $10 \%$ to $80 \%$, and had periods of significant $\mathrm{NO}_{2}^{-}$accumulation (Figure 1f). In contrast, Table 2 shows that organic carbon removal efficiency varied less among reactors, indicating that presumed C-processing guilds were less impacted by dilution rate in our systems. This is consistent with the fact that $\mathrm{C}$-processing organisms tend to have higher maximum specific growth rates than $\mathrm{N}$-processing organisms in systems with complex organic media (Rittman and McCarty, 2003).

Determination and verification of $L E$ and observed $L E$ among guilds

LEs were calculated for each guild to quantify sensitivity to initial conditions in measured abundances, using the method of Rosenstein et al. (1993, 1994). As background, positive LEs indicate that a time series is 'divergent' and mean that subtle differences in initial conditions can result in totally different trajectories, which is a signature trait of chaotic behavior. Figure 2 shows that LEs were positive for all guilds and that LEs were robust relative to assumptions made in the calculations (that is, narrow error bars). To verify that calculated LEs were deterministic rather than stochastic - a critical issue in proving chaos in short, noisy time series - a series of additional tests were performed on the data (Peng et al., 1995; Barahona and Poon, 1996; Schreiber and Schmitz, 1996; Kantz and Schreiber, 2004; Rohani et al., 2004).

Modified Pimm-Redfearn and detrended fluctuation analyses showed consistent 'pink-shifting' in guild time-series data (see Supplementary Information for details), indicating that long-term deterministic trends were not obscured by noise. Furthermore, nonlinear Volterra-Wiener series models consistently fit data better than linear models, 


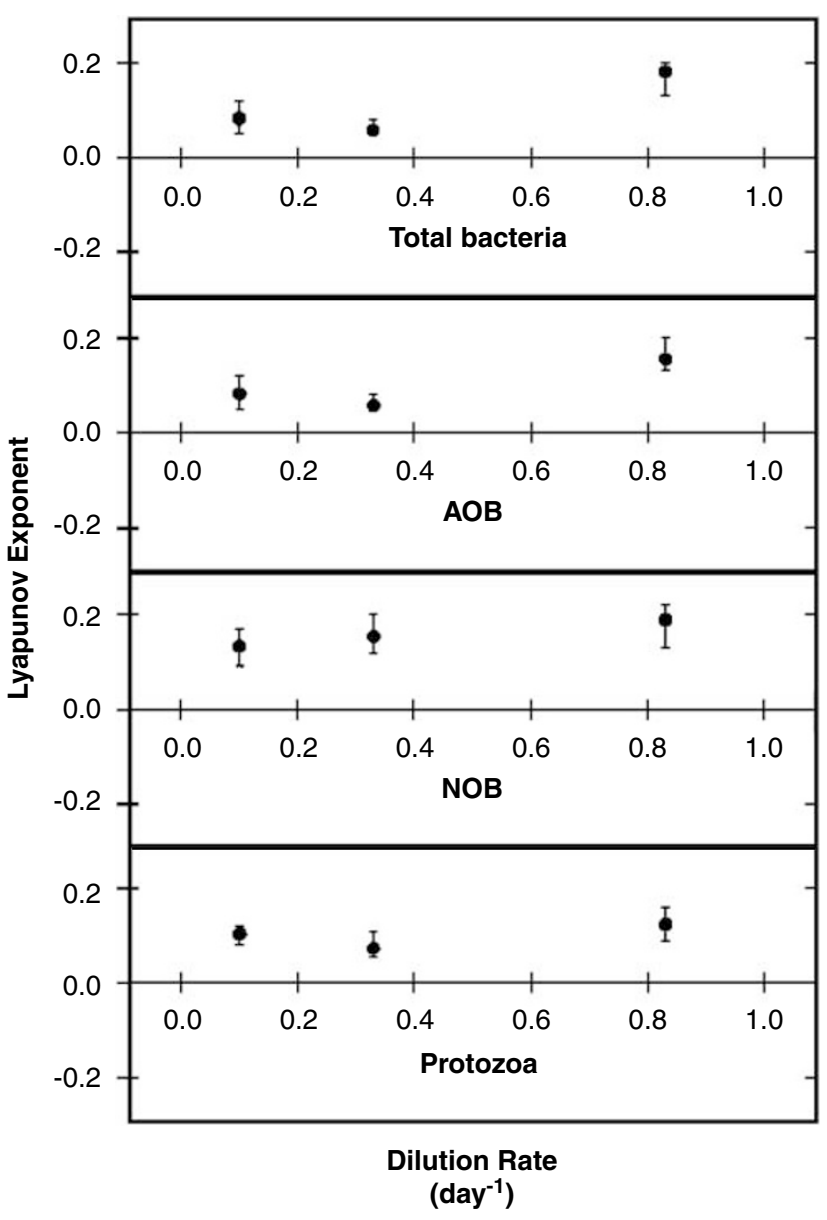

Figure 2 LEs for total bacteria, AOB, NOB and protozoa in the three dilution rate chemostats. Error bars refer to the range of LE based on six estimates, using 5 and 6 consecutive points for the least squares fit of the log-transformed divergence data and embedding dimensions of 4, 5 and 6 . The mean point is shown for each set of estimates for each dilution rate and guild.

suggesting a visible nonlinear component to each signal. Finally, standard Fourier surrogate analysis showed that prediction error in the nonlinear Volterra-Wiener model for all guilds (apart from protozoa) was most often smallest in distributions over 20 series that included 19 surrogate series. Although this positive test result for nonlinearity was not of $95 \%$ statistical significance in all cases, these results, combined with consistently positive LEs and pink-shifted signals, strongly indicate deterministic nonlinear behavior rather than a noise-dominated signal, and can be used to examine the basis of stability in nitrification.

Although LEs were always positive, they differed among guilds and dilution rates. LEs were highest in the high-dilution rate reactor for total bacteria, protozoa and AOB, and significantly correlated with each other in all three reactors. This correlation implies that dynamics among the major guilds likely reflects a predator-prey impacted system. In contrast, LEs for NOB were high at all dilution rates and did not correlate with protozoan LEs (nor any other guild), suggesting that another ecological interaction may explain better the dynamics of this guild.

Correlation between guild variance and abundances, and nitrification performance

Although LEs were positive for all guilds, Figure 1 and Table 2 show that nitrification was only erratic in the $0.83 \mathrm{day}^{-1}$ reactor. Therefore, to investigate relationships between guild dynamics and process efficiency, bivariate correlation analysis was performed on guild rolling CVs and abundances, and Nconversion efficiency in the $0.83 \mathrm{day}^{-1}$ unit. The abundances of NOB, total bacteria, predator and AOB all significantly positively correlated with nitrification efficiency, and AOB CV significantly negatively correlated (all $P<0.05$ ). However, further partial correlation analysis indicated that only NOB abundance and AOB CV independently correlated with efficiency $(P<0.01)$. Figure 3 summarizes the significant relationships between NOB abundance $\left(r^{2}=0.27, P<0.01\right)$ and AOB CV $\left(r^{2}=0.14, P<0.01\right)$, and nitrification efficiency. These data provide an experimental explanation for why instability patterns differ for NOB relative to the other guilds, which has major implications to predictability in the nitrification process.

\section{Discussion}

Theoretical models have indicated that mutualistic systems conditionally display chaotic behavior, depending upon initial population sizes, the extent of the 'mutual benefit' of the interaction and the fragility of the mutualism (obligate versus facultative) (Dean, 1985; Lopez-Ruiz and Fournier-Prunaret, 2004). Specifically, when mutual benefit is high and the mutualism is fragile, quasi-periodic and even chaotic behavior is predicted (Lopez-Ruiz and Fournier-Prunaret, 2004). Given that NOB strongly depends on $\mathrm{AOB}$ for its preferred electron donor and AOB depends on NOB to remove toxic $\mathrm{NO}_{2}^{-}$ (Kowalchuk and Stephen, 2001; Rittman and McCarty, 2003), the mutual benefit between AOB and NOB is high. Furthermore, AOB and NOB are comparatively less diverse than many other key guilds (for example, heterotrophs or denitrifying bacteria), which suggests that redundancy among species is likely small, especially in a chemostat, and fragility of the interaction is likely high in the guilds. Therefore, the AOB-NOB mutualism is of the type that might be prone to chaotic instability, which our data confirm.

Figure 1 shows that when AOB becomes increasingly variable in the reactor near washout, NOB becomes destabilized in an amplified manner, resulting in unprocessed $\mathrm{NO}_{2}^{-}$. We suggest that as $\mathrm{NO}_{2}^{-}$accumulates, AOB becomes impaired and further destabilized, and a downward spiral results due to feedback within the mutualism. In general 


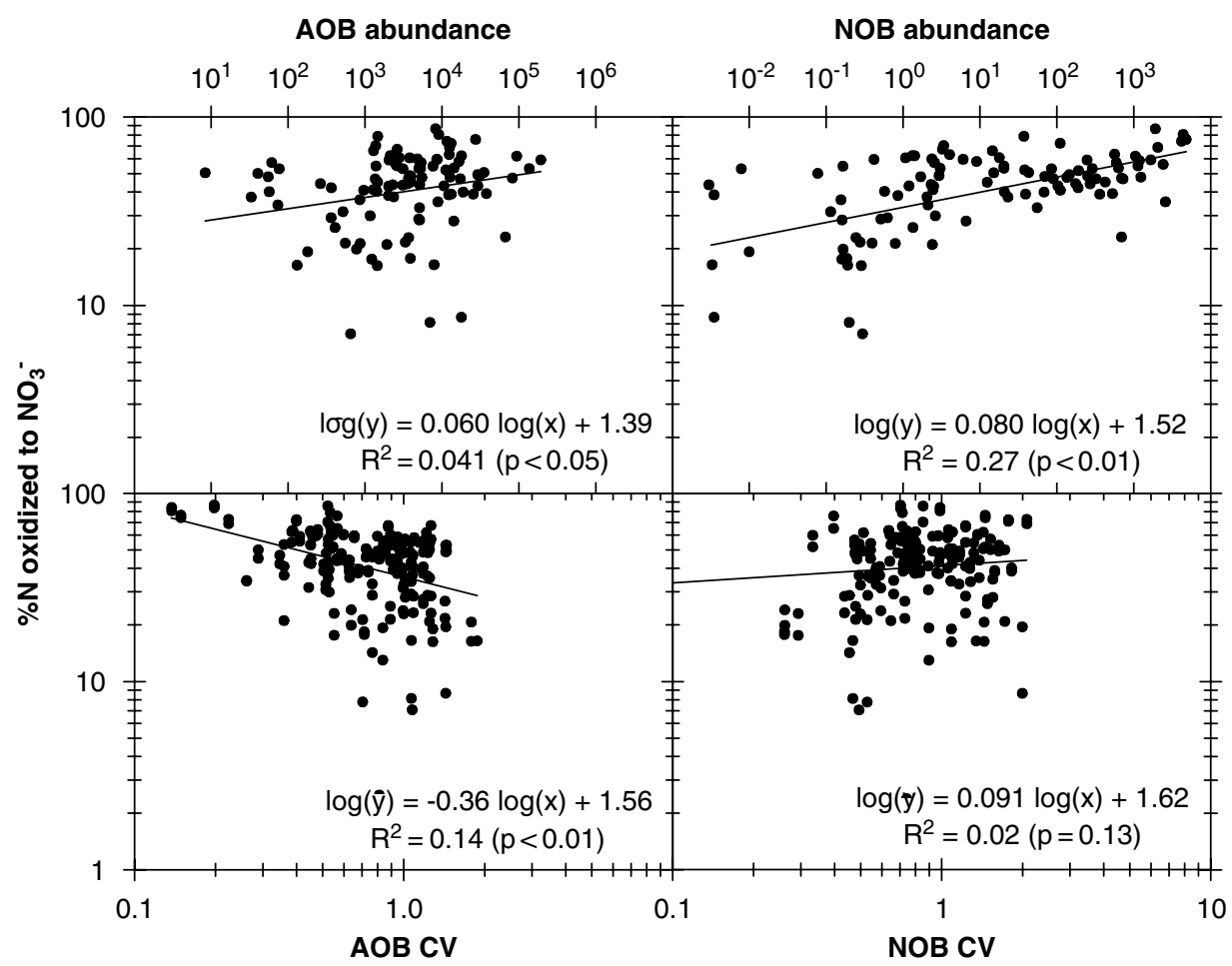

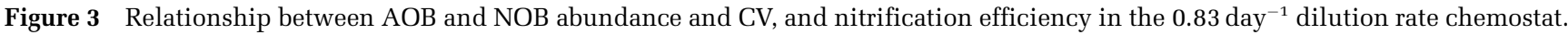
All data were log-transformed to satisfy normality criteria for statistical analysis. CVs were calculated as rolling values according to the wavelength of oscillations in the abundance data for each time series. Nitrification efficiency is defined as the percent conversion of total input nitrogen (that is, $\mathrm{TN}$, or the sum of influent $\mathrm{NH}_{3}-\mathrm{N}$ and organic- $\mathrm{N}$ ) to $\mathrm{NO}_{3}^{-}$in the chemostat effluent.

terms, we suggest that when AOB abundances become more variable (for any reason), the innate sensitivity of NOB to initial conditions (as suggested by consistently high and positive LE) causes both guilds to become increasingly unstable and uncoupled, which makes the mutualism unpredictable as has been seen in many practical applications (Rittman and McCarty, 2003). The specific reason why NOB are so sensitive is not clear, although their lack of diversity, narrow nutritional needs and reliance on a 'toxic' electron donor are possible explanations (Kowalchuk and Stephen, 2001; Wagner and Loy, 2002; Wagner et al., 2002).

These observations have various implications. On a general level, the data show that NOB stability is dramatically linked to AOB instability, which we propose is why this mutualism is so unpredictable. In our experiment, near-collapse only occurred close to washout, when the whole community became highly unstable. Although we likely saw greater instability here than one would see in a full-scale bioreactor (for example, waste treatment unit with greater biodiversity) or in a soil (with greater compartmentalization among organisms within the system), we suggest the innately fragile relationship between AOB and NOB might result in destabilization under almost any conditions.

For example, we propose that 'fragile mutualism' is an alternate explanation for why nitrification is known to be so sensitive to exogenous inhibitors
(Balmelle et al., 1992; Jonsson et al., 2000). Such sensitivity may simply result from the fact that even small perturbations in $\mathrm{AOB}$ can trigger amplified negative responses in NOB that uncouples the interaction. Furthermore, exogenous inhibitors might only be one factor that triggers variability in the AOB guild (other factors are higher dilution rates, predator-prey effects or the differential activity of phage on AOB versus NOB guilds), and that unpredictability in nitrification is fundamental to the fragile AOB-NOB relationship. Given this, we propose that monitoring of AOB CV (or the equivalent) in real systems could be a useful tool for forecasting nitrification instability (analogous to strategies proposed for other ecosystems (Scheffer and Carpenter, 2003; Carpenter and Brock, 2006)), which would have great value in biotechnical applications of the process.

Four final synoptic observations can be made. First, chaotic behavior exists in complex microbial communities; however, not all guilds in the same system are equally 'dynamic' at all times and consideration is needed when contemplating the assumption of chaos in ecosystems. Second, chaotic behavior does not always translate to inefficient microbial guild function. All guilds tested displayed chaotic behavior in all reactors; however, no major loss in C-processing efficiency was seen in any reactor and N-processing efficiency only declined in the 0.83 day $^{-1}$ reactor. In fact, it has been suggested 
that systems at 'the edge of chaos' exhibit selforganization and other features that can actually promote successful function in the presence of modest disturbances (Sprott et al., 2005). Third, we predict that observations of instability in nitrification will foreshadow similar observations in other microbial mutualisms that are fragile with high mutual benefit; the obvious example being methanogenesis. Finally, although chaotic instability in nitrification impacts biotechnological applications, a possibly more important implication of this result is related to stability in the biogeochemical Ncycle (Vitousek et al., 1997). Specifically, if nitrification is prone to chaotic behavior, this process might be particularly susceptible to temperature increases, and reduced stability of the N-cycle might be an additional consequence of climate change.

\section{Acknowledgements}

We thank T Curtis, H Daims, J Dolfing, T Ebihara, M Giesen, I Head, A Layton, D Ofiteru and W Sloan for assistance on various elements of the project. The work was supported by the Kansas Research Development Program (DWG), NSF EPSCOR (DWG), EU Marie Curie Excellence Programme Grant MEXT-CT-2006-023469 (DWG, CWK and KB) and NSF Grants DMS-0139824 and DMS-0513438 (ESV).

\section{References}

APHA (American Public Health Association), American Water Works Association and World Environment Federation (1998). Standard Methods for the Examination of Water and Wastewater, 20th edn. APHA: Washington, DC, USA.

Balmelle B, Nguyen KM, Capdeville B, Cornier JC, Deuin A. (1992). Study of factors controlling nitrite buildup in biological processes for water nitrification. Water Sci Technol 26: 1017-1025.

Barahona M, Poon CS. (1996). Detection of nonlinear dynamics in short, noisy time series. Nature 381: 215-217.

Becks L, Hilker FM, Malchow H, Jurgens K, Arndt H. (2005). Experimental demonstration of chaos in a microbial food web. Nature 435: 1226-1229.

Bergey DH, Holt JG, Krieg NR, Sneath PHA. (1994). Bergey's Manual of Determinative Bacteriology. Lippincott Williams \& Wilkins: Baltimore, MD, USA.

Carpenter SR, Brock WA. (2006). Rising variance: a leading indicator of ecological transition. Ecol Lett 9: 308-315.

Coskuner G, Ballinger SJ, Davenport RJ, Pickering RL, Solera R, Head IM et al. (2005). Agreement between theory and measurement in quantification of ammonia-oxidizing bacteria. Appl Environ Microbiol 71: 6325-6334.

Costantino RF, Desharnais RA, Cushing JM, Dennis B. (1997). Chaotic dynamics in an insect population. Science 275: 389-391.

Daims H, Ramsing NB, Schleifer KH, Wagner M. (2001). Cultivation-independent, semiautomatic determination of absolute bacterial cell numbers in environmental samples by fluorescence in situ hybridization. Appl Environ Microbiol 67: 5810-5818.
Dean AM. (1985). The dynamics of microbial commensalisms and mutualisms. In: Boucher DH (ed). The Biology of Mutualism. Croom Helm: Kent, UK, pp 270-304.

Fry JC. (1990). Direct Methods and Biomass Estimation. Academic Press: London, UK.

Funasaki E, Kot M. (1993). Invasion and chaos in a periodically pulsed mass-action chemostat. Theoret Pop Biol 44: 203-224.

Fussmann GF, Ellner SP, Shertzer KW, Hairston NG. (2000). Crossing the Hopf bifurcation in a live predator-prey system. Science 290: 1358-1360.

Gentile ME, Jessup CM, Nyman JL, Criddle CS. (2007). Correlation of functional instability and community dynamics in denitrifying dispersed-growth reactors. Appl Environ Microbiol 73: 680-690.

Harms G, Layton AC, Dionisi HM, Gregory IR, Garrett VM, Hawkins SA et al. (2003). Real-time PCR quantification of nitrifying bacteria in a municipal wastewater treatment plant. Environ Sci Technol 37: 343-351.

Hawkins SA, Robinson KG, Layton AC, Sayler GS. (2006). A comparison of ribosomal gene and transcript abundance during high and low nitrite oxidizing activity using a newly designed real-time PCR detection system targeting the Nitrobacter spp. 16S-23S intergenic spacer region. Environ Eng Sci 23: 521-532.

Hermansson A, Lindgren PE. (2001). Quantification of ammonia-oxidizing bacteria in arable soil by real-time PCR. Appl Environ Microbiol 67: 972-976.

Huisman J, Weissing FJ. (1999). Biodiversity of plankton by species oscillations and chaos. Nature 402: 407-410.

Jonsson K, Grunditz C, Dalhammar G, Jansen JL. (2000). Occurrence of nitrification inhibition in Swedish municipal wastewaters. Water Res 34: 2455-2462.

Juretschko S, Loy A, Lehner A, Wagner M. (2002). The microbial community composition of a nitrifyingdenitrifying activated sludge from an industrial sewage treatment plant analyzed by the full-cycle rRNA approach. Syst Appl Microbiol 25: 84-99.

Kantz H, Schreiber T. (2004). Nonlinear Time Series Analysis. Cambridge University Press: Cambridge, UK.

Klappenbach JA, Saxman PR, Cole JR, Schmidt TM. (2001). rrndb: the Ribosomal RNA Operon Copy Number Database. Nucleic Acids Res 29: 181-184.

Kooi BW, Boer MP. (2003). Chaotic behaviour of a predator-prey system in the chemostat. Dyn Contin Discr Impulsive Syst B 10: 259-272.

Koops H-P, Purkhold U, Pommerening-Röser A, Timmermann G, Wagner M. (2003). The lithoautotrophic ammonia oxidizing bacteria. In: Dworkin M, Falkow S, Rosenberg E, Schleifer K-H, Stackebrandt E (eds). The Prokaryotes: An Evolving Electronic Resource for the Microbial Community. Springer-Verlag: New York.

Kowalchuk GA, Stephen JR. (2001). Ammonia-oxidizing bacteria: a model for molecular microbial ecology. Ann Rev Microbiol 55: 485-529.

Kowalchuk GA, Stephen JR, DeBoer W, Prosser JI, Embley TM, Woldendorp JW. (1997). Analysis of ammoniaoxidizing bacteria of the beta subdivision of the class Proteobacteria in coastal sand dunes by denaturing gradient gel electrophoresis and sequencing of PCR-amplified 16S ribosomal DNA fragments. Appl Environ Microbiol 63: 1489-1497.

Loferer-Krössbacher M, Klima J, Psenner R. (1998). Determination of bacterial cell dry mass by transmission electron microscopy and densitometric image analysis. Appl Environ Microbiol 64: 688-694. 
Lopez-Ruiz R, Fournier-Prunaret D. (2004). Complex behavior in a discrete coupled logistic model for the symbiotic interaction of two species. Math Biosci Eng 1: 307-324.

May RM. (1974). Stability and Complexity in Model Ecosystems. Princeton University Press: Princeton, USA.

Miura Y, Hiraiwa MN, Ito T, Itonaga T, Watanabe Y, Okabe S. (2007). Bacterial community structures in MBRs treating municipal wastewater: relationship between community stability and reactor performance. Water Res 41: 627-637.

Park H-D, Wells GF, Bae H, Criddle CS, Francis CA. (2006). Occurrence of ammonia-oxidizing Archaea in wastewater treatment plant bioreactors. Appl Environ Microbiol 72: 5643-5647.

Peng CK, Havlin S, Stanley HE, Goldberger AL. (1995). Quantification of scaling exponents and crossover phenomena in nonstationary heartbeat time-series. Chaos 5: 82-87.

Posch T, Loferer-Krossbacher M, Gao G, Alfreider A, Pernthaler J, Psenner R. (2001). Precision of bacterioplankton biomass determination: a comparison of two fluorescent dyes, and of allometric and linear volume-to-carbon conversion factors. Aquat Microb Ecol 25: 55-63.

Provenzale A, Smith LA, Vio R, Murante G. (1992). Distinguishing between low-dimensional dynamics and randomness in measured time-series. Physica $D$ 58: $31-49$.

Rittman BE, McCarty PL. (2003). Environmental Biotechnology: Principles and Applications. McGraw-Hill: New York, USA.

Rohani P, Miramontes O, Keeling MJ. (2004). The colour of noise in short ecological time series data. Math Med Biol 21: 63-72.

Rosenstein MT, Collins JJ, Deluca CJ. (1993). A practical method for calculating largest Lyapunov exponents from small data sets. Physica D 65: 117-134.
Rosenstein MT, Collins JJ, Deluca CJ. (1994). Reconstruction expansion as a geometry-based framework for choosing proper delay times. Physica D 73: 82-98.

Ruttner-Kolisko A. (1977). Suggestions for biomass calculations of plankton rotifers. Arch Hydrobiol 8: 71-76.

Scheffer M, Carpenter SR. (2003). Catastrophic regime shifts in ecosystems: linking theory to observation. Trends Ecol Evol 18: 648-656.

Schreiber T, Schmitz A. (1996). Improved surrogate data for nonlinearity tests. Phys Rev Lett 77: 635-638.

Spieck E, Hartwig C, McCormack I, Maixner F, Wagner M, Lipski A et al. (2006). Selective enrichment and molecular characterization of a previously uncultured Nitrospira-like bacterium from activated sludge. Environ Microbiol 8: 405-415.

Sprott JC, Vano JA, Wildenberg JC, Anderson MB, Noel JK. (2005). Coexistence and chaos in complex ecologies. Phys Lett A 335: 207-212.

Turchin P. (2003). Complex Population Dynamics: An Empirical/Theoretical Synthesis. Princeton University Press: Princeton, USA.

Vayenas DV, Pavlou S. (1999). Chaotic dynamics of a food web in a chemostat. Math Biosci 162: 69-84.

Vitousek PM, Aber JD, Howarth RW, Likens GE, Matson PA, Schindler et al. (1997). Human alteration of the global nitrogen cycle: sources and consequences. Ecol Appl 7: 737-750.

Wagner M, Loy A. (2002). Bacterial community composition and function in sewage treatment systems. Curr Opin Biotechnol 13: 218-227.

Wagner M, Loy A, Nogueira R, Purkhold U, Lee N, Daims H. (2002). Microbial community composition and function in wastewater treatment plants. Antonie Van Leeuwenhoek 81: 665-680.

Wagner M, Nielsen PH, Loy A, Nielsen JL, Daims H. (2006). Linking microbial community structure with function: fluorescence in situ hybridizationmicroautoradiography and isotope arrays. Curr Opin Biotechnol 17: 83-91.

Supplementary Information accompanies the paper on The ISME Journal website (http://www.nature.com/ismej) 